\title{
On the Role of Gaze in the Organization of Turn-Taking and Sequence Organization in Interpreter-Mediated Dialogue
}

\begin{abstract}
This paper contributes to the growing line of research that takes a multimodal approach in the study of interpreter-mediated dialogues. Drawing on insights from Conversation Analysis and multimodal analysis, we investigate how extended multi-unit turns unfold with interventions of an interpreter and, more specifically, what is the role of gaze in this process. The analysis is based on videos of interpreter-mediated dialogues (Dutch-Russian) recorded with mobile eyetracking glasses. Responding to recent discussions on the organization of gaze in social interaction, we argue that the interpreter's gaze direction contributes both to the local management of turn-taking (next-speaker selection) and to sequence organization. More specifically, we show how interpreter's gaze orientation bears on the negotiation of possible transition relevance places and how it contributes to the smooth continuation of the projected extended multi-unit turn. Thus, interpreters in face-to-face interactions are necessarily involved in the process of turn allocation and sequence organization and this is made evident through their gaze conduct.
\end{abstract}

\section{Keywords}

Multimodality, interpreter-mediated dialogue, multi-unit turns, gaze in interaction, turn-taking, conversation analysis, next-speaker selection, transition relevance place

\section{Introduction}

The organization of turn-taking in interpreted encounters is in many aspects different from turntaking in same-language interactions (Bot 2005, Englund Dimitrova 1997, Li 2015, Wadensjö 1998). In interpreter-mediated conversations, the two primary speakers usually have no or limited understanding of each other's language and therefore communicate with the aid of an interpreter. Generally, the interpreter provides a rendition of one speaker's talk in every second turn, in the language of the other speaker (Bot 2005, Englund Dimitrova 1997, Wadensjö 1998). Interpreters also have different needs and interests concerning turn-taking than the primary speakers: the interpreter usually benefits from shorter primary speaker's turns in order to be able to provide close renditions of the preceding talk (Bot 2005: 112). Moreover, recent studies have shown that the interpreter, rather than merely relaying speech content as a linguistic 
'conduit', is an active participant who is critically engaged in the negotiation of meaning and in the coordination of the interaction (Angelelli 2000, Baraldi and Gavioli 2012, Bolden 2000, Davidson 2002, Llewellyn-Jones and Lee 2014, Wadensjö 1998). Thus interpreter-mediated talk is necessarily a joint accomplishment between the two speakers and the interpreter, who acts both as a translator and a coordinator during the talk. This also means that speakers "may not retain control on extended parts of the conversation" and "must yield part of their interactional power and share responsibilities for the management of the interaction" with the interpreter (Pasquandrea 2011, 456). Thus, given its complex participation framework interpreter-mediated interaction offers researchers unique opportunities for the study of collaborative and multimodal processes of turn-taking and sequence organization.

Previous research has demonstrated that multimodal resources (speech, gaze, body posture etc.) are of crucial importance for the management of turn-taking in consecutively interpreted conversations with an on-site interpreter (e.g. Bot 2005, Davitti and Pasquandrea 2017, Mason 2012, Pasquandrea 2011, Wadensjö 1998). Especially gaze conduct appears to have an important function in this process (Bot 2005, Davitti 2013, Lang 1978, Mason 2012, Pasquandrea 2011). Lang's (1978) pioneering study revealed that by not gazing at the primary speakers, the interpreter can miss out important turn management cues. Lang argued that "constant visual monitoring by the interpreter of his clients, especially at turns or possible turns, is an absolute necessity" (Lang 1978, 241). Further studies have demonstrated the importance of gaze direction for the negotiation of transition relevance places (Pasquandrea 2011) and for the allocation of turns (Mason 2012) in interpreter-mediated encounters. However, no systematic conceptualization has been developed on the way in which interpreter's gaze is organized with reference to turn-taking and sequence organization in consecutively interpreted conversations with an on-site interpreter.

This paper examines the relevance of gaze in turn-taking and sequence organization in the context of triadic, interpreter-mediated interactions with professional interpreters by drawing on the insights from conversation analysis (e.g. Sidnell and Stivers 2013) and multimodal analysis (e.g. Mondada 2007). More specifically, it focuses on the interpreter's involvement in the construction of 'larger projects' or multi-unit turns (e.g. extended descriptions and pieces of advice) that are 'chunked' (Bot 2005) into shorter units in order to allow the interpreter to provide a rendition of the talk piecemeal. Of special interest are those moments at the end of the interpreter's turn, when "transfer can take place to any of the primary speakers" (Bot 2005: 112). Our research questions are the following: 
How is chunking of such longer multi-unit turns multimodally accomplished in interpreter-mediated talk? What is the role of gaze in this process? How does the interpreter display her understanding that a multi-unit turn is in progress?

We will focus on the moment-by-moment multimodal negotiation of such chunked extended tellings and analyze the role of the interpreter's gaze direction in this process. In order to get fine-grained gaze information from all participants simultaneously, we used a dataset of nine interpreter-mediated interactions in a university setting that were recorded with mobile eyetracking glasses (see section 4). On the basis of detailed single case analyses in two sequential environments (first-pair parts and multi-unit turns), the study shows that (a) the interpreter's gaze at the end of her turn is actively employed as a mechanism for next-speaker selection (see also Auer 2017, section 2) and (b) that interpreter's gaze orientation is guided by her understanding of the ongoing sequence organization. The interrelatedness of gaze in the process of turn-taking and sequence organization is particularly visible in the process of 'chunking' of projected multi-unit turns (section 5). During 'chunking', the interpreter displays her orientation towards the previous speaker even before the end of her ongoing turn. We also discuss how this bears on the negotiation of a possible transition relevance place for the recipient and argue that interpreter's gaze orientation is constitutive for sequence organization in face-to-face interpreted interaction. Finally, we discuss the implications of this study for our understanding of turn-taking in interpreter-mediated interaction and for the regulatory functions of gaze.

\section{Turn-taking and gaze in face-to-face interaction}

The organization of turn-taking in human interactions has been studied extensively by researchers working in Conversation Analysis (Sacks et al., 1974) who are interested in analyzing how interactants manage to coordinate their turns in a finely tuned way. Sacks et al. (1974) observed that generally 'one party talks at a time' and that this is achieved through finely tuned, moment-by-moment coordination between interlocutors' turns (e.g. Mondada 2007, Schegloff 2000,). According to Sacks et al. (1974), every turn consists of one or multiple turn constructional units (TCUs), i.e. potentially complete, meaningful utterances, such as sentences, clauses, phrases and words (Clayman 2013). On the basis of syntactic, prosodic, pragmatic and embodied cues, the recipient can anticipate the type of unit that is being produced and foresee its possible completion (Auer 2005, Ford and Thompson 1996, Lerner 1991, Mondada 2007, Sacks et al. 1974, Selting 2000, Stivers and Rossano 2010). The moment in 
talk where the transition to a next speaker becomes possible is referred to as the transition relevance place (TRP). Sacks et al. (1974) defined two types of techniques for turn allocation in spontaneous talk: (i) the current speaker may select someone else to speak next ("currentselects-next') or (ii) the participants can self-select to produce the next turn. As for self-selection techniques the next speaker can project or claim incipient speakership with an appositional beginning (e.g. well, so), vocal or nonvocal resources (e.g. an audible inbreath, opening of the mouth), gaze and hand gesture (for an overview, see Hayashi 2013). For example, Mondada (2017) has shown that by pointing before the completion of the current turn, listeners progressively establish themselves as possible next speakers and thereby publicly display their understanding of the turn-in-progress in real-time (Mondada 2007). In his study on gaze direction in dyadic interactions, Kendon (1967) found that incipient speakers tend to look away just before speaking, which may signal to their interlocutors that they are about to take the floor. This result was replicated in an eye-tracking study by authors (2017).

As for current-selects-next techniques, the most effective way for the current speaker to select the following speaker is by producing a first pair-part (e.g. a question) in combination with some form of addressing (an address term and/or gaze direction at the interlocutor) (Hayashi 2013). While address terms are not frequently used in ordinary conversations (Hayashi 2013: 170), selection through gaze is part and parcel of face-to-face interaction. Early studies by Kendon (1967) and Duncan (1972) argued that speaker gaze has a 'floor apportionment' function, in that the speakers tend to shift their gaze away at turn-beginning and gaze back toward the recipient near turn completion in order to signal that they are ready to hand over the floor to the recipient. Similarly, Bavelas et al. (2002) found that speaker gaze is an important resource for the mobilization of listener's minimal responses in face-to-face talk. More recently, Rossano (2012) reconsidered previous work on the regulatory functions of gaze by claiming that gaze is not primarily organized by reference to turns-at-talk and that there is "no evidence that speakers use gaze as a turn-yielding cue". According to Rossano, gaze is "mainly organized in relation to sequences of talk and the development of courses of action or ongoing interactional projects" $(2013,319)$. He observed that, for instance, tellings require a more sustained gaze by the recipient toward the speaker than questions. Rossano's claims were supported by Streeck (2014).

However, aforementioned studies primarily focused on gaze conduct in conversations with two participants. Gaze direction is of particular importance for the organization of turn-taking in conversations with more than two participants, where it is can be unclear who will be the next 
speaker. Goodwin (1979) and Lerner (2003) have argued that directing gaze at a co-participant in a multi-party interaction is an explicit way of addressing an utterance, but that its success depends on the gazing practices of other participants; both the addressed and the non-addressed participant must see the gaze direction of the current speaker (see also Hayashi 2013). Building up on this distinction between currently addressed versus non-addressed participants in multiparty talk, Auer (2017) argues for making an analytical distinction between gaze for nextspeaker selection and gaze for addressee selection. According to Auer $(2017,12)$ :

"addressee selection (by gaze) and next-speaker selection (by gaze) are temporally ordered. While addressees may vary during an emerging turn, the co-participant who is gazed at toward the end of a speaker's turn is the one who is selected as next speaker"1.

At the same time, Auer (2017) acknowledges that gaze alone as a cue for next-speaker selection is less effective than multimodal techniques for next-speaker selection (such as gaze in combination with an address term). Despite the above-mentioned limitation with the use of gaze for the allocation of turns, the distinction between gaze for next-speaker selection and gaze for addressee selection will prove to be particularly useful in the context of interpreter-mediated interactions, as this study will show.

\section{Extended tellings in interpreter-mediated talk}

This paper focuses on a specific form of sequence organization, namely the production of multiunit turns or extended tellings (Houtkoop and Mazeland 1985, Ford 2004, Sacks et al. 1974, Schegloff 1982, Selting 2000). Multi-unit turns involve elaborate actions such as extended descriptions, story tellings, pieces of advice and the like (Houtkoop and Mazeland 1985, Selting 2000). In contrast to adjacency pairs, which project a transition relevance place immediately after the first-pair-part, turn-taking during the production of multi-unit turns is temporarily suspended (Selting 2000). The recipient will refrain from taking the turn until syntactically, prosodically, pragmatically and visually recognizable turn completion has been reached (Selting 2000, see also Clayman 2013, Houtkoop and Mazeland 1985). Selting (2000) distinguishes non-final TCU's and final TCU's with "operative TRP's" in the production of multi-unit turns (see Figure 1). According to Selting, multi-unit turns are an "interactive achievement in which speakers suspend TRPs, and recipients refrain from making use of suspended TRPs" $(2000,487)$. However, the recipients can - and are indeed expected to - make contributions during the production of a multi-unit turn, in the form of acknowledgment tokens, 
assessments or head nods, through which they confirm their recipiency (see Goodwin 1986, Houtkoop and Mazeland 1985, Stivers 2008). Extended tellings also require more sustained gaze by the recipient towards the speaker (Rossano 2012, 124). Therefore, the recipient must be able to recognize or project that a multi-unit turn is in progress, in order to be able to respond in an appropriate way ${ }^{2}$. As noted by Rossano:

For this coordination to be successful, the collaboration of the co-participant is not only important but necessary, as s/he could block the production of an extended telling by simply taking the floor at the first transition relevance place. This implies that the coparticipant must be able to recognize that, at least approaching the transition relevance place, the current TCU is not going to be the last one of the telling but rather there will be further ones. (Rossano 2012, 69)

The speaker employs various practices to signal a multi-unit turn and to secure recipiency of the interlocutors in order to be able to bring the multi-unit turn to its completion (Stivers 2013). Typical practices include list-initiating markers ('first of all', see Schegloff 1982) or story prefaces (Sacks 1974); rising intonation (Duncan 1972, Selting 2000); gestural holds (Duncan 1972) and markers of pragmatic incompletion (Sack et al. 1974, Schegloff 1982) that project turn continuation.

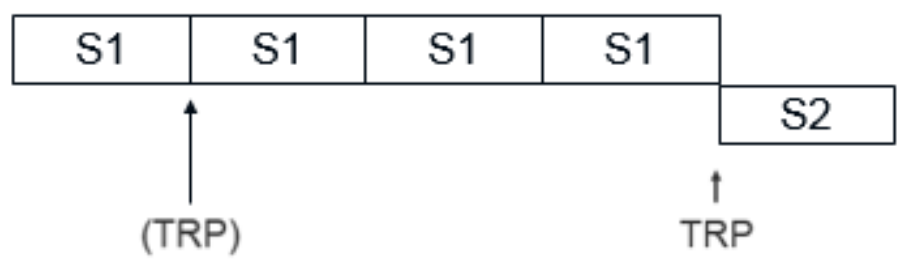

Figure 1. A schematic representation of extended tellings in same-language interaction (adapted from Rossano 2012)

The production of extended tellings is a more complex matter in consecutively interpreted interactions, where 'nextness' of the primary speakers' turns is disrupted by the interpreter's renditions. In interpreter-mediated interactions, extended multi-unit turns may lead to the interpreter's inaccurate and ambiguous renditions, which could reduce the quality of communication between the primary speakers ( $\mathrm{Li} 2015)$. Therefore the primary speakers may choose to 'chunk' longer multi-unit turns into shorter units (see Figure 2) in order to allow the interpreter to make renditions piecemeal (Bot 2005, 117). Chunking also reduces the time that the other participant has to wait for the interpreter's rendition, allowing him or her to respond (e.g. by producing an assessment or a head nod) during the progression of the multi-unit turn 
and thus confirm his or her recipiency. It is then at the end of the multi-unit turn that turn transfer to the other primary speaker takes place (Bot 2005, 117).

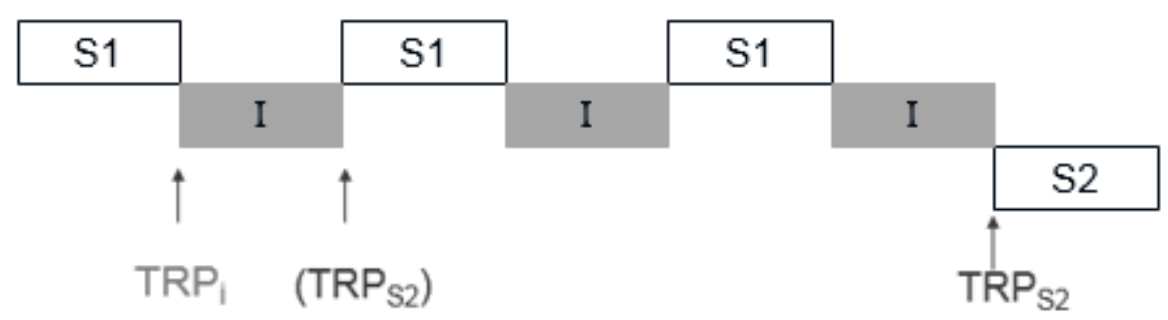

Figure 2. A schematic representation of the production of 'chunked' extended tellings in interpreter-mediated talk

However, when an extended telling is delivered in shorter units, "each piece is translated as a decontextualized whole" and "participants in conversation (including the interpreter) may draw premature conclusions about the points a speaker wishes to make" (Wadensjö 1998, 234). Of particular interest are the moments at the end of the interpreter's turn; as the primary speaker whose talk is being translated lacks knowledge of the other language, (s)he has less control over the turn transfer between the interpreter and the recipient. Therefore close collaboration and understanding between the primary speaker and the interpreter is crucial in this process (see also Merlino 2014). The importance of smooth chunking of multi-unit turns is demonstrated by Licoppe and Veyrier (forthcoming) in court proceedings with asylum seekers where one of the parties is interacting via video link; if chunking does not run smoothly between the asylum seeker and the (remote) interpreter, this can lead to negative inferences on the part of the asylum seeker. We now examine in detail how chunking in face-to-face interpreter-mediated dialogues is accomplished in real-time and what is the role of gaze in this process. We focus on those moments at the end of the interpreter's turn where, according to Bot, "turn transfer can take place to any of the speakers" $(2005,112)$. However, Bot did not take into account the sequential context in which turn transfer takes place. By comparing the interpreter's gaze conduct in two sequential environments (first pair-parts of adjacency pairs and non-final TCUs of an extended telling in progress), we analyze the role of gaze in the process of sequence projection and turntaking in interpreter-mediated talk. 


\section{Data and Method}

The data for this study consist of nine encounters (ca. 180 minutes in total) between a Russianspeaking foreign student, a Dutch-speaking university counsellor and an interpreter at the university of Leuven in Belgium. In total, three counsellors, three students and three interpreters participated in this study. The students and the counsellors were previously unacquainted and had very limited knowledge of each other's language. Each talk was interpreted consecutively into both languages by one of the three qualified and experienced interpreters that took part in this study. All participants gave their written informed consent prior to the recordings.

The conversations were mainly focused on students' study program, integration into the local university, reasons for studying in Belgium, and other questions or concerns they had. The participants were seated in triangular formation, in line with the code of conduct for community interpreters in Belgium (see Figure 3), with the interpreter in the middle and on more or less equal distance from the primary speakers. Such seating arrangement maximizes mutual eye contact between interlocutors and the opportunity to monitor each other's actions, allowing us to highlight some systematic regulatory features of gaze in interactions with an on-site interpreter ${ }^{3}$.

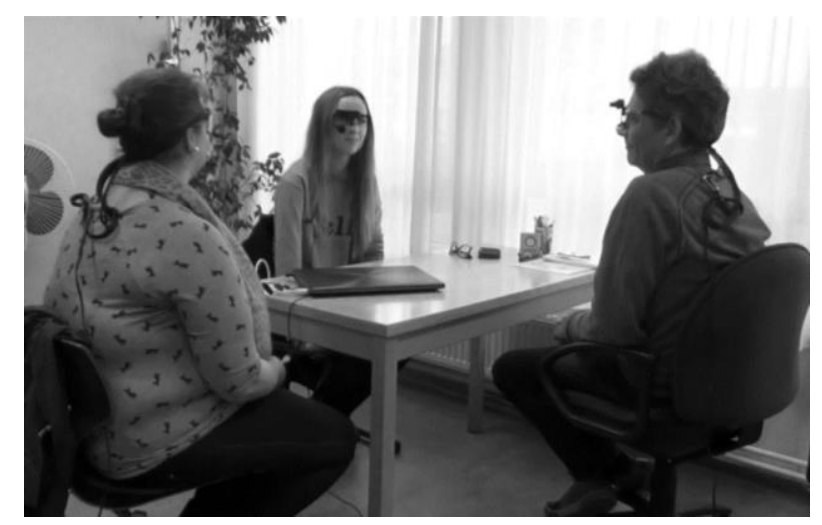

Figure 3. Seating arrangement of the participants. (from left to right: interpreter - student - counsellor)

In order to get detailed information on the gaze behavior of the participants, each participant was wearing a mobile eye-tracker (Pupil Pro Binocular Glasses and Arrington Gig-E60) during the conversation. Mobile eye-trackers resemble spectacle frames with two integrated cameras that record both the participants' field of vision and their eye-movements ${ }^{4}$. In contrast to previous studies on interpreter-mediated interactions, where usually one of the participant perspectives is left out of the analysis (Authors, forthcoming) mobile eye-tracking enabled us to study gaze conduct of all three participants at the same time. An additional camera (Sony HDR-FX1000E) was set up to provide a profile shot of the interaction (Figure 3). For a detailed 
description of the dataset and of the recording method, see Authors (forthcoming). The recordings were transcribed, translated and annotated regarding gaze direction (see Authors forthcoming, for a description of the annotation procedure), turn beginnings and endings, sequence types and other (non)verbal behavior in the open-source video annotation tool ELAN (Wittenburg et al. 2006). The results reported in this article are based on an examination of 48 cases in which a primary speaker's multi-unit turns were 'chunked' into shorter units. In the following sections, we show that the interpreter's gaze direction at the end of the turn is dependent on the type of action that (s)he projects, by comparing the interpreter's gaze behavior at the end of a first pair-part of a question-answer sequence and at the end of a non-final TCU of a multi-unit turn.

\section{Analysis}

\subsection{First pair-parts of an adjacency pair: gaze at the selected next speaker}

In contrast to extended tellings, where turn transfer between interlocutors is temporarily suspended, first pair-parts such as questions project a responding action of a particular type (Sacks et al. 1974). By responding, the recipients display their understanding of the preceding action. In the present data set, interpreters always orient their gaze toward the addressee and expected responder while rendering a question (see also Stivers and Rossano 2010). An example of this pattern is shown in Extract 1. Note that all figures in the extract are screenshots from the eye-tracking camera worn by the interpreter and thus represent the latter's gaze direction (indicated with a colored dot). The transcription symbols can be found in the annex. Prior to the excerpt, the student (STU) has been telling that he will be going abroad for a research stay during the summer.

\section{Extract 1}

1 CNS

wanneer\# zou je terug hier \#zijn?

when would you be back here?

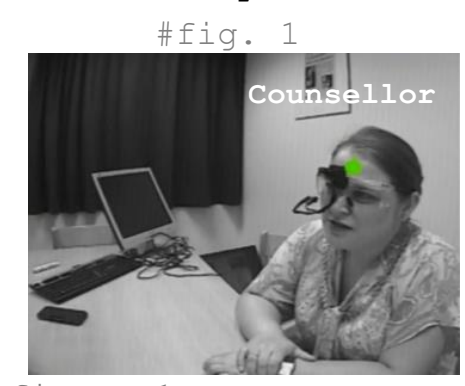

figure 1

а ког\#да вы вернётесь в Бельгию?

and when are you coming back to Belgium? 


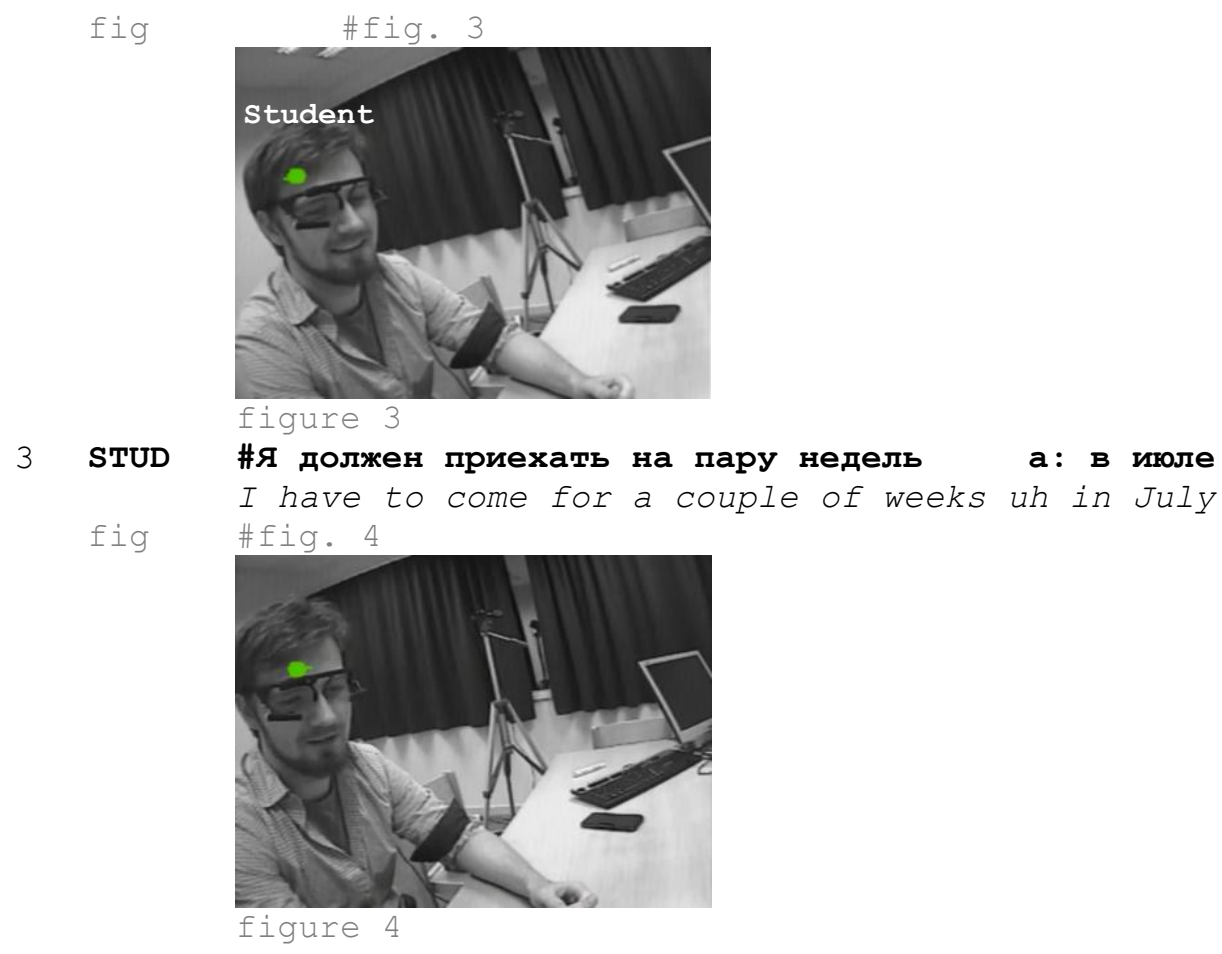

In line 1, the counsellor (CNS) asks a question while gazing at the Russian student, who is the addressee and the expected responder. Already the first word (the adverb 'when') allows the interpreter (INT) to ascertain what type of action counsellor is initiating. Even before completion of the question, the interpreter starts to shift her gaze to the table in front of her (Figure 2), thus anticipating the end of the current turn and displaying her readiness to take the floor. Such early gaze shift provides evidence for the interpreter's online processing of the speaker's utterance (on 'projection', see e.g. Auer 2015). In line 2, the interpreter reproduces the question while gazing at the student (Figure 3). Gazing at a particular co-participant is treated as an 'explicit' method of addressing (see Hayashi 2013, Stivers and Rossano 2010). The interpreter thus displays her alignment with the projected action of the previous turn through her gaze orientation; by maintaining her gaze at the student while she orients to the relevance of his response (line 3). In this sequential position it might be difficult to maintain Auer's analytical distinction between speaker-gaze for addressee selection and speaker gaze for next-speaker selection, as the student is both the addressee and the expected next speaker. Against this background, we will now turn to the interpreter's gaze conduct in the process of chunking of multi-unit turns. 


\subsection{Chunking of multi-unit turns}

\subsubsection{Immediate gaze shift to the previous speaker at turn-end: Close collaboration}

In the following, we focus on the interpreter's gaze conduct during stepwise production of multi-unit turns. Most multi-unit turns in our data were initiated by a question of the other primary speaker ("second-position tellings", see Mandelbaum 2013). In the following extract, the counsellor is engaged in an explanation about wedding ceremonies in Belgium. Again, the figures in the extract are screenshots from the eye-tracking camera worn by the interpreter and thus represent her perspective.

\section{Extract 2}

$1 \quad$ CNS dus er wordt eerst een=uh so there is first an uh (0.2) je hebt ten \#eerste \#al

(0.3) twee ceremonies, you have first of all

\section{西} two ceremonies,

en (.) je moet (.) uiteraard burgerlijk ook trouwen and you have to obviously also get married at the Records office in het (.) \#stadhuis of in het ge\#meentehu\#is. city hall or at the town hall.
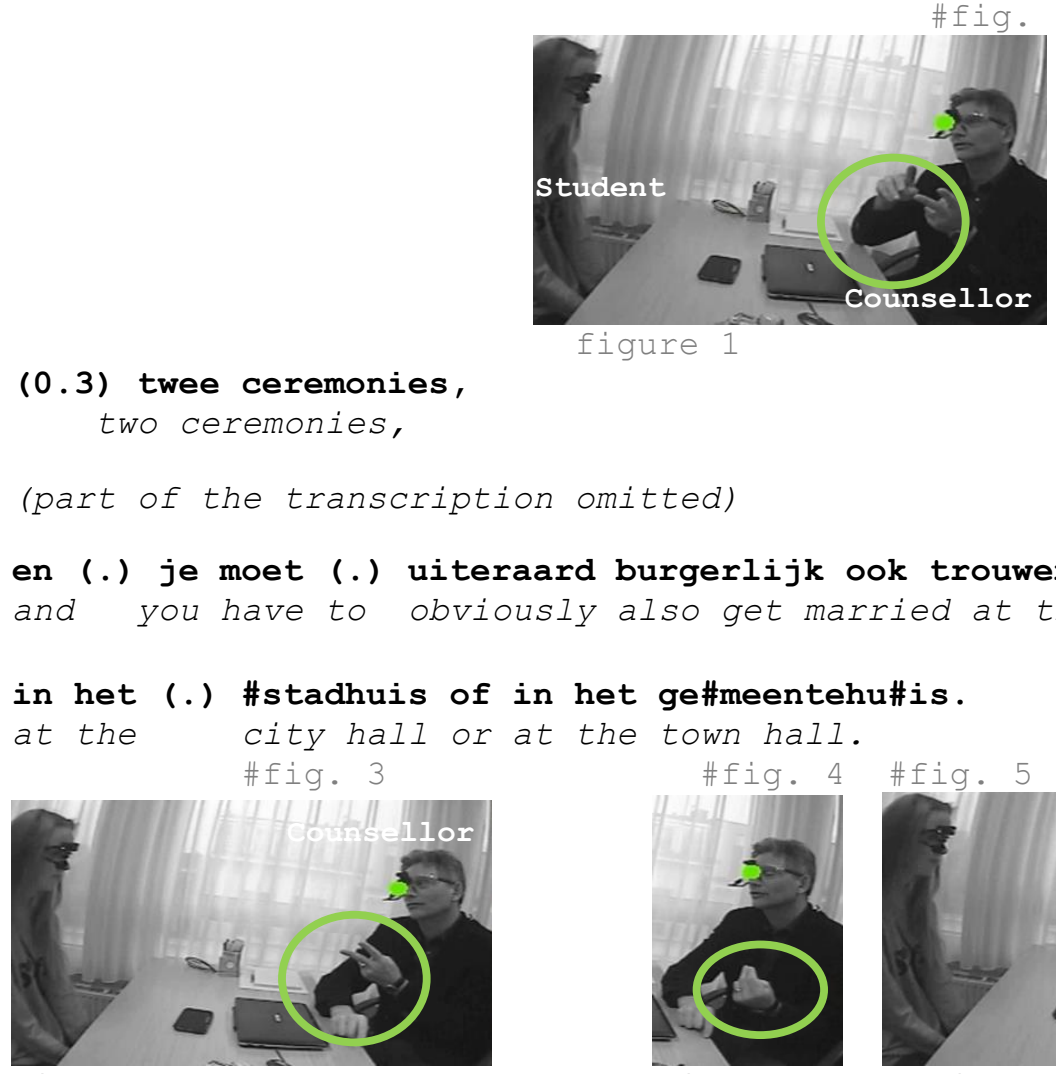

figure

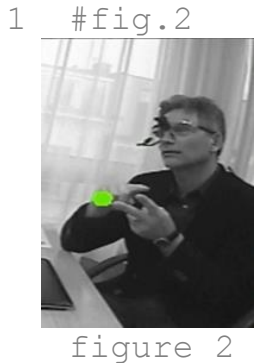

figure 3

INT

.h вдесь тоже две: $\epsilon$ : церемонии

.h here are also two uh ceremonies

(part of the transcription omitted) 


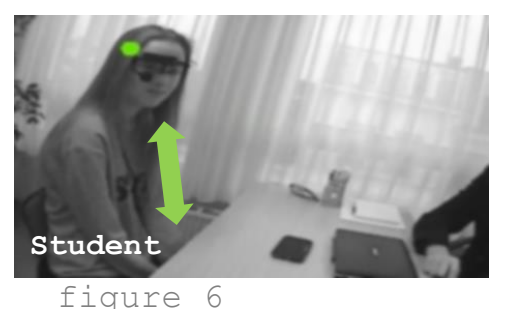

(0.2) в вагсе это обычно $є$ : или в ратуше где-то в г\#ороде.

at the Records Office usually uh or in the town hall somewhere in the city.

$(0.4) \#(0.3)$

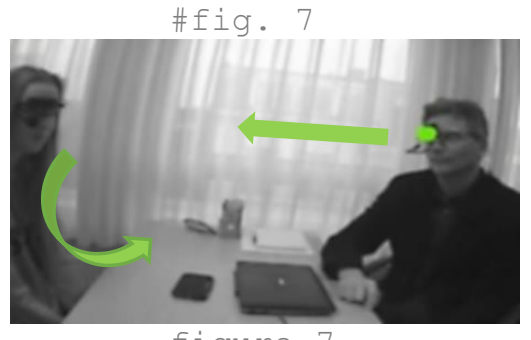

figure 7

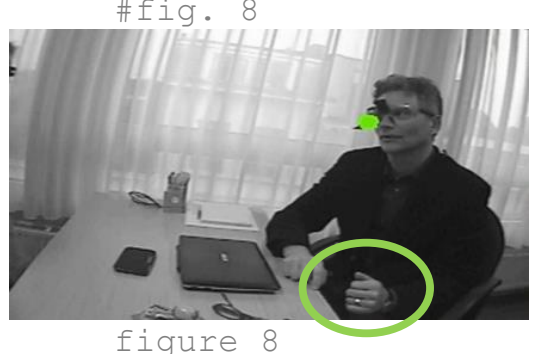

11 CNS en vaak eer\#st 't stadhuis en d\#an de kerk, and often first in the city hall and then the church,

fig \#fig. 9

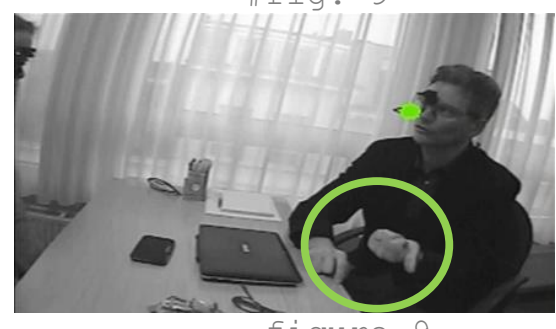

figure 9 \#fig. 10

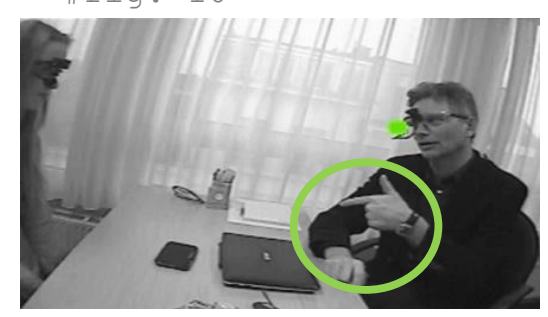

figure 10

$(0.2) \#$

fig

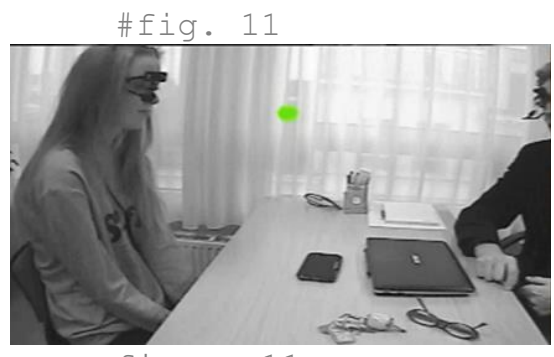

13 INT

и обычното в ратуше, а потом ц\#ерковь,

(...)

fig

and usually in the city hall, and then the church, \#fig. 12 


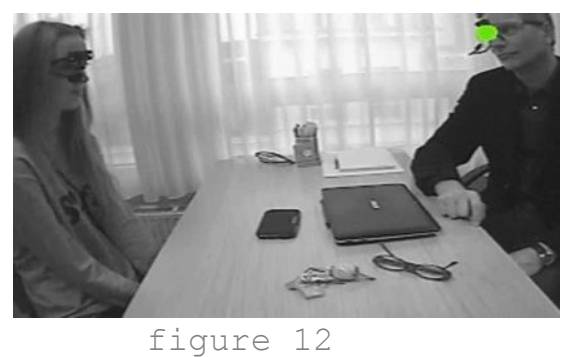

In line 1, the counsellor (CNS) starts with a list-initiating marker 'first of all' (see also Schegloff 1982) accompanied by a co-speech counting gesture (Figure 1) that signals to the recipient that an extended description will follow (see also the interpreter's gaze shift towards the counsellor's hands in Figure 2). From lines 1 to 5, the counsellor produces his turn while looking at the student ${ }^{5}$. All the while, the interpreter maintains her gaze at the counsellor (Figure 1). Towards the end of his turn (line 5), which is produced with a falling intonation contour and with a retracting gesture (Figures 3-4) (see also Duncan 1972, Kendon 1967), the interpreter shifts her gaze toward a middle position (Figure 5) and produces an audible inbreath. Her gaze shift together with the audible inbreath clearly belongs to the pre-onset phase of her turn (Schegloff 1996, Mondada 2007) and projects her incipient speakership. In line 6, she starts rendering the counsellor's utterance into Russian. Interestingly, toward the end of her turn, she does not maintain her gaze at the student, who is the addressee of her turn, but immediately shifts her gaze back to the counsellor (Figure 7). Following the interpreter's gaze movement,

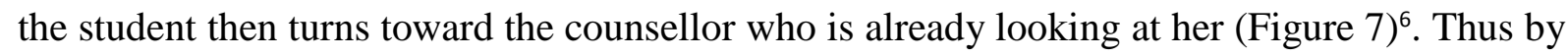
shifting her gaze, the interpreter makes it publicly visible that she orients towards continuation of the counsellor's turn and thereby selects him as next speaker. In this sequential environment her gaze shift works as a kind of continuer, produced to display her ongoing understanding "that an extended unit is in progress and is not yet completed" (Schegloff 1982, 84). At the same time, by shifting her gaze before the end of her turn, the interpreter is in a way blocking the completion points of her turn from being treated as transition places by the student (see also Houtkoop and Mazeland 1985). In this way, the interpreter is closely collaborating in the production of the extended telling.

During the pause in line 10, the counsellor starts lifting his hand again (Figure 8) and establishing himself as a speaker (see also Mondada 2007). The conjunction 'and' at the beginning of his turn (line 11) makes it recognizable as an increment of the turn-so-far and marks continuity with the previous utterance. The counsellor supports the chronology of the described events with hand gestures: 'first' (pointing to the left, Figure 9) and 'then' (pointing to the right, Figure 10). All the while, he gazes at the student, who is the principal recipient of 
his telling. Again, the interpreter anticipates a possible transition relevance place in line 11 by shifting her gaze to a middle position (Figure 11). She starts speaking after a slight pause (line 12), during which the counsellor retracts his gesture. Although the lowering of the gesture indicates the end of the TCU, he finishes his utterance with a rising intonation contour, projecting 'more to come'. Interestingly, the student seems to anticipate turn continuation as well, as she keeps her head oriented towards the counsellor (see Figure 9) during the interpreter's short rendition in line $13^{7}$. Once again, the interpreter shifts her gaze to the counsellor before the completion of her rendition in line 13.

Thus, chunking is a collaborative achievement between the speaker and interpreter. The interpreter relies on a combination of available cues (syntactic structure, intonation, pragmatics and gesture deployment) in deciding when possible completion has been reached and when to take the turn. It can also be observed that through her gaze shift, the interpreter projects both the incipient end of her own turn and continuation of the previous speaker's telling.

Extract 3 further illustrates the phenomenon. Here the speaker selects the interpreter as the next speaker by directing her gaze towards her ${ }^{8}$.

\section{Extract 3}

1 CNS er is in vlaanderen de laatste jaren heel wat veranderd there has been a lot of change in Flanders in recent years

2 in het hoger onderwijs, in the higher education,

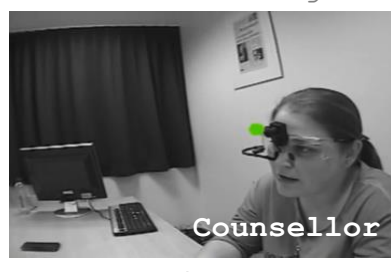
\#fig. 2

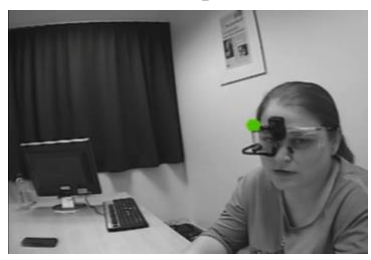

4 INT

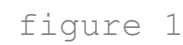

figure 2

$[\mathrm{mm} \mathrm{hm}$,

5 INT . hh\#

fig

\#fig. 3

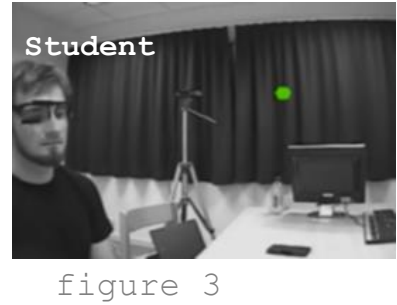



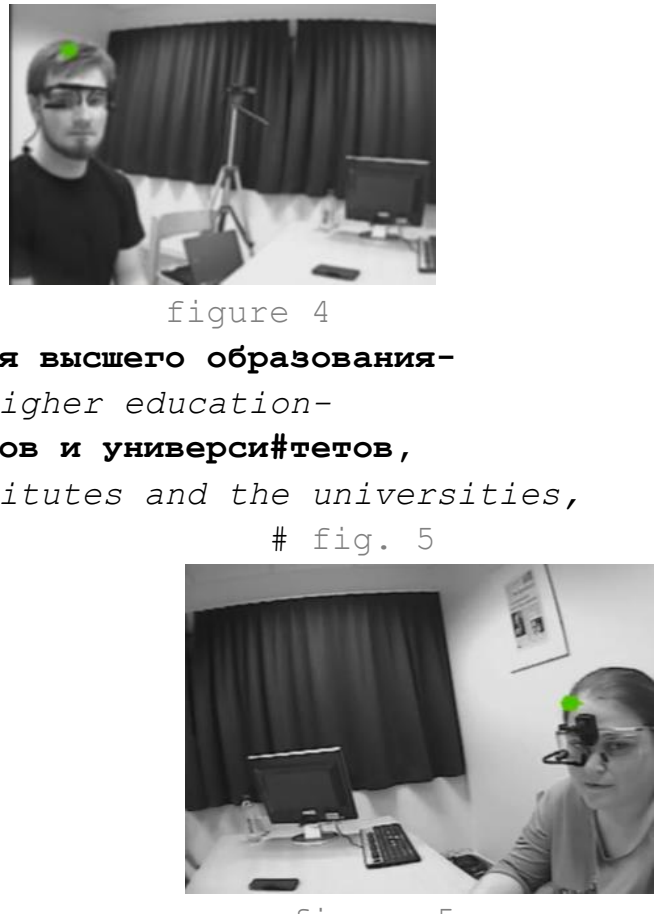

\section{(.)}

11 CNS .h uhm dus vroeger (...)

.h uhm so before (...)

The counsellor is explaining to the student why there are two universities in the city of Antwerp. The screenshots represent the interpreter's gaze direction. From lines 1 to 3 , the counsellor is addressing her explanation to the Russian student, while the interpreter is looking at her (Figure 1). Towards the end of her utterance in line 3, she moves her gaze toward the interpreter (Figure 2), thereby inviting her to take the turn. At the same time, the pragmatic incompletion and rising intonation of the counsellor's turn indicate that her explanation will be continued ('at colleges and universities then,'). The counsellors in the present data set rarely use gaze in combination with verbal address to give the floor to the interpreter. In this context, the use of verbal address by the counsellor would disrupt the progress of the multi-unit turn and bring the interpreter's presence more to the foreground. Therefore a smooth turn transfer between the counsellor and the interpreter during the production of a chunked multi-unit turn necessarily depends on the interpreter's projection of the upcoming transition space and continuous understanding of the ongoing action (see also section 5.2.2). 
At line 4, the interpreter projects possible completion by producing a minimal response (' $\mathrm{mm}$ hm'). During an audible inbreath (line 5), she shifts her gaze to a middle position as a way of displaying her incipient speakership. Comparable to extract 2, the interpreter projects turn continuation by moving her gaze to the expected next speaker (the counsellor) towards the end of her turn-in-progress.

A quantitative analysis reveals that in $90 \%$ of non-final TCU's of projected multi-unit turns, the interpreter shifts her gaze to the previous speaker even before the end of her current TCU. We annotated the timing of those early gaze shifts (defined as the difference (in milliseconds) between the time that interpreter's turn-final gaze ${ }^{9}$ shift starts and the moment that the interpreter's turn-in-progress ends) in ELAN and found that the average timing of the interpreter's gaze shift was $-645 \mathrm{~ms}$ (median $=-464 \mathrm{~ms}$; minimum value $=0 \mathrm{~ms}$; maximum value $=-1864 \mathrm{~ms}$ ). If we assume that speakers need about $600 \mathrm{~ms}$ to plan their speech (Levinson and Torreira 2015), then such an early gaze shift by the interpreter may contribute to the shortening of the transition space between the interpreter and the primary speaker.

Also, through those gaze shifts the interpreter is blocking the completion points of the TCU's from being treated by the recipient as normal transition-relevance-places (cf. Houtkoop and Mazeland 1985, Selting 2000) and thus project the continuation of the extended telling.

To summarize, our analysis has shown how the interpreter projects completion of her turn and continuation of the developing action with her gaze, ensuring in this way a smooth continuation of the primary speaker's multi-unit turn. These observations are also in line with Lang, who observed that it is important for the interpreter to maintain visual contact with all primary speakers, "but especially with the one who is talking" $(1978,233)$, or in this case, who is expected to resume the talk.

\subsubsection{No gaze shift to the previous speaker at turn-end: Temporary incongruity in sequence formation}

a) The selected speaker does not take the turn

As shown in the previous extracts, the interpreters closely collaborate in the construction of a 'chunked' extended telling by anticipating transition relevance places and projecting turn continuation towards the end of her rendition, as becomes evident through their gaze behavior. 
In the following extract, which is a continuation of Extract 3, we present a deviant case ${ }^{10}$ in which continuation of a multi-unit turn is projected by the speaker, but not by the interpreter. This can lead to a temporary incongruity in the progression of the projected multi-unit turn. Note that the screenshots first represent the interpreter's and then (from line 6) the counsellor's perspective.

\section{Extract 4}

1 CNS dus vroeger had \#je de universiteiten en de hogescholen, so before you had the universities and the colleges,

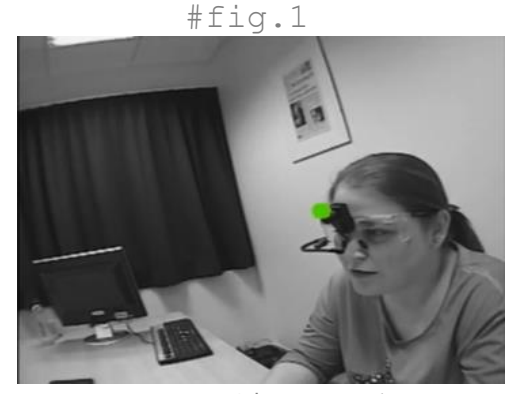

en op die hogescholen werden ook een aantal opleidingen and at colleges also a number of courses were

van academisch niveau \#aangebod[en.

offered at academic level.
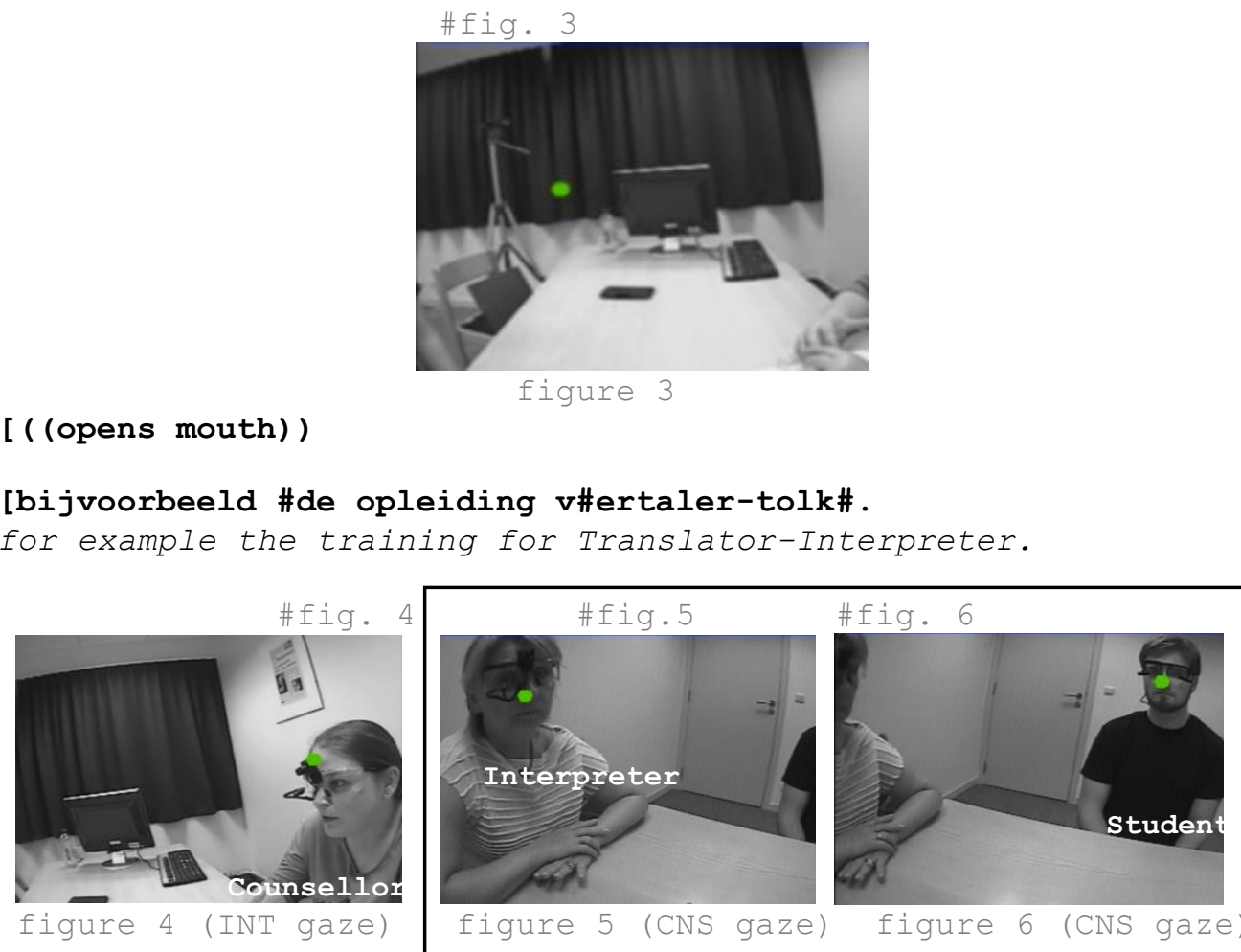

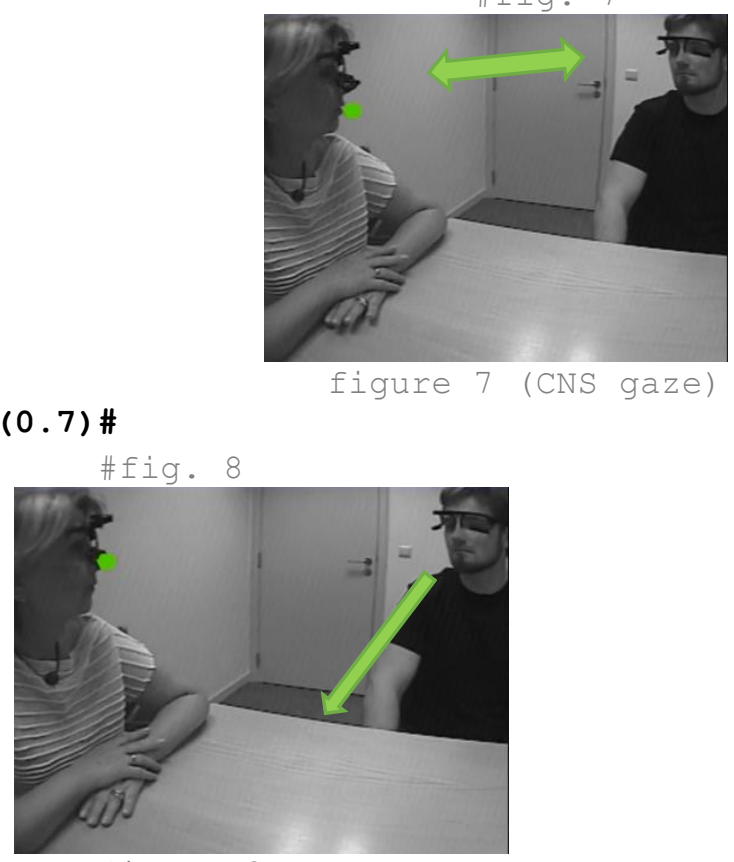

11 CNS

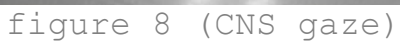

Fig . $\mathrm{h} \#$

\#fig. 9

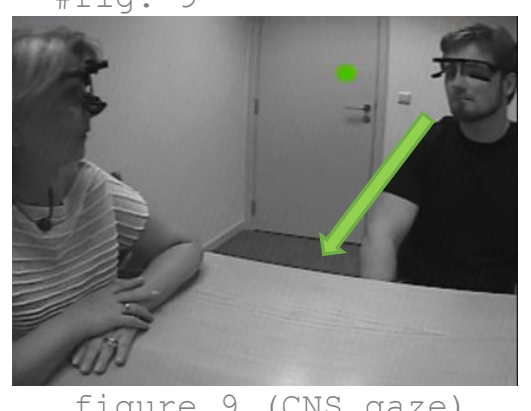

$(0.5) \#$

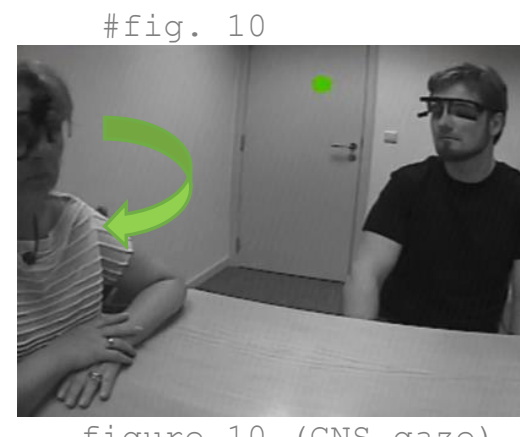

The counsellor starts with the explanation of the situation 'before' (in line 1) while looking at the student. In line 3, the counsellor's utterance ends with a falling intonation contour, which is treated by the interpreter as turn completion; she displays her incipient speakership with an 
acknowledgment token ('mh hm'; 1. 4) while opening her mouth and shifting her gaze towards a middle position (Figure 3). The interpreter's gaze shift is thus part of the pre-onset phase of her turn. However, the interpreter immediately abandonds her incipient speakership as the counsellor continues with an expansion ('for example...' at line 6). During this expansion, the counsellor quickly looks at the interpreter and then back at the student (Figures 5-6). By looking at the interpreter, she projects an imminent completion point and displays her orientation towards the interpreter as next speaker (for a similar observation, see Extract 3). Although the counsellor's utterance is syntactically and prosodically complete, her explanation about the current situation has not yet reached its pragmatic completion.

In line 7, the interpreter starts rendering the counsellor's utterance, while being engaged in mutual gaze with the student. At the end of her turn, the interpreter maintains her gaze at him, thus selecting him as the next speaker (Figure 7). There is a notable pause at line 10, during which the student moves his gaze towards the table in front of him; he appears to be disengaging from the conversation and signaling that he is not going to take the turn. The interpreter's gaze orientation makes turn-transition and thus recipient reaction relevant ${ }^{11}$. The pause turns into a place "where a response could have been produced but was not" (Couper-Kuhlen and Ono 2007). The student's gaze withdrawal from the interpreter has not so much to do with his orientation toward the possibility of ending the sequence (Rossano 2012), but rather with his refusal to take up the turn after being selected to respond by the interpreter through gaze. This example nicely illustrates how gaze as a turn-allocation technique is "an inviting instead of obliging technique for next-speaker selection" (Auer 2017). The interpreter maintains her gaze at him (Figure 8), possibly in an attempt to elicit a response (Stivers and Rossano 2010). In this way, she appears to be reshaping the trajectory of the primary speaker's talk and projecting a transition relevance place $^{12}$.

After registering that the interpreter is not oriented towards her (Figures 7-8), the counsellor self-selects by producing an audible inbreath (Schegloff 2000) in line 11 while shifting her gaze to a middle position (Figure 9). After a slight pause (line 12), the interpreter eventually moves her gaze toward the counsellor (Figure 10). Only when the interpreter displays availability again, does the counsellor continue with her turn (line 13). This example nicely shows how speakers may display sensitivity to the gaze (and head) orientation of the interpreter in the process of chunking.

As shown in this extract, the interpreter is doing more than just translating the talk; she shapes/co-manages the progression of the multi-unit turn through her gaze. 


\section{b) The selected speaker takes the turn}

The following excerpt illustrates another case in which the interpreter does not immediately shift her gaze back to the previous speaker who has projected a multi-unit turn, but displays her orientation to the recipient as next speaker. However, in contrast to the previous example, the recipient (STU) takes the opportunity to take the turn and initiate a question.

\section{Extract 5}

1 CNS die krijgen bijvoorbeeld hé \#van studentenvoorzieningen they get for example eh? from the student services

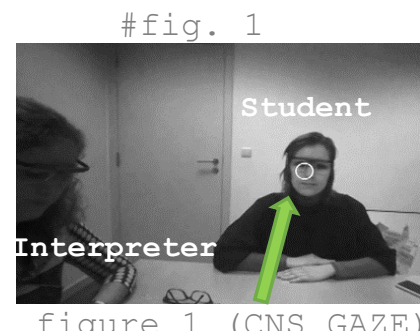

ik heb het \#eventjes (.) op\#engezet ook voor jou, I've just opened it (.) for you as well,
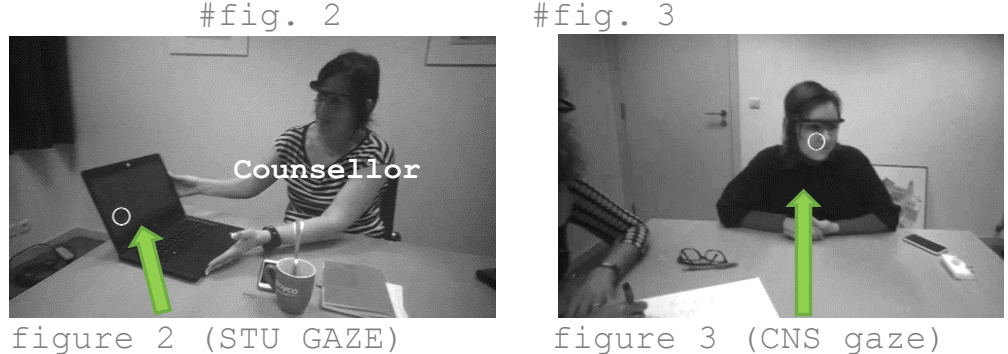

(0.4) die krijgen een aantal mogelijkheden aangeboden (0.4) they are offered a number of options en dat is ook toegan\#kelijk voor de (.)\# Erasmusstudenten. and those are also accessible for the Erasmus students.

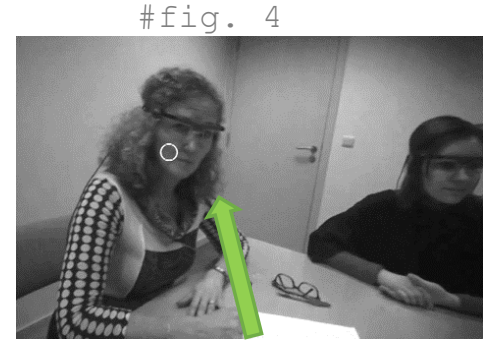

figure 4 (CNS gaze)

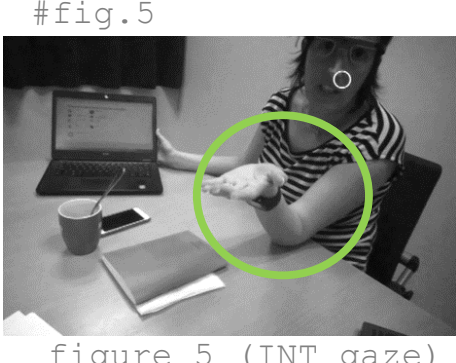

figure 5 (INT gaze)

5 INT \#mh $\mathrm{hm}:$ ?

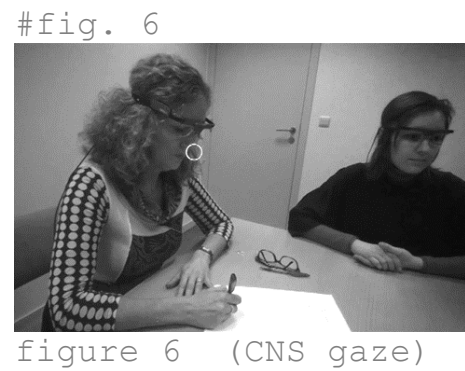




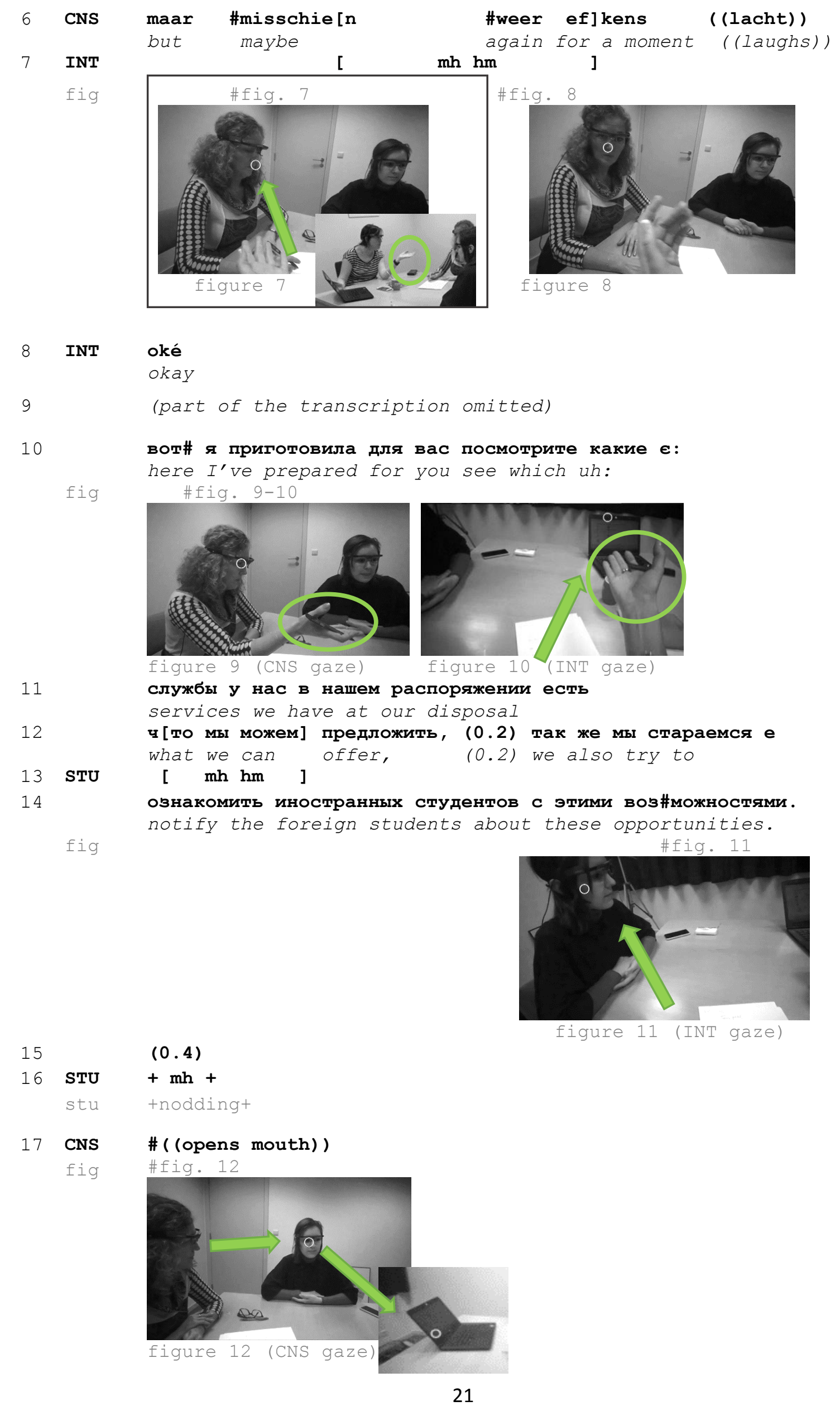



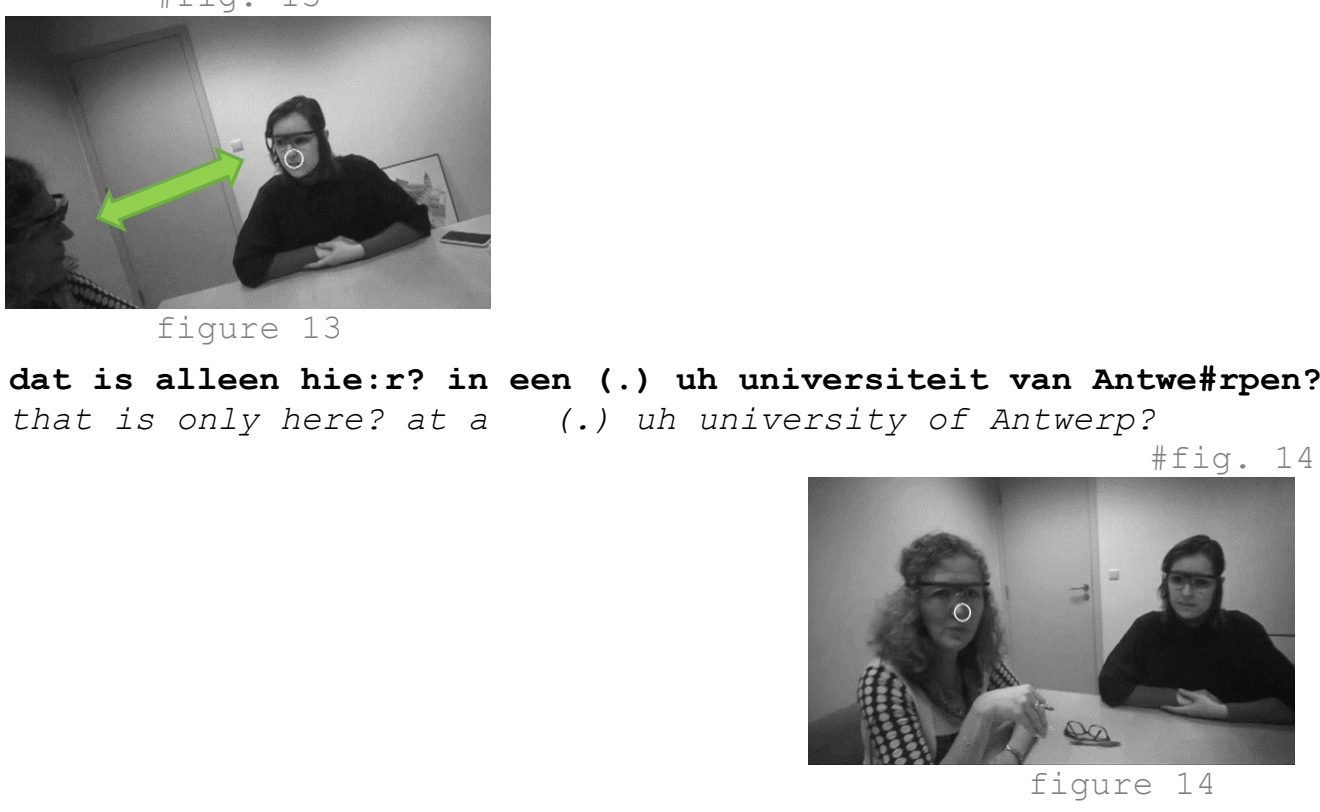

Prior to this excerpt, the student had asked how the integration of foreign students proceeds at the university. The counsellor is explaining here that the university organizes various student activities that are open for foreign students as well. At one point during her explanation (in line 2), she turns her laptop screen with the opened web page of the university student service towards the student (Figure 2). The student maintains her gaze at the laptop screen until the end of the counsellor's utterance. Near the end of her TCU (line 4), the counsellor looks at the interpreter, thereby inviting her to take the floor. This is supported through her deictic gesture (Figure 5). Instead of taking the turn, the interpreter produces a continuer ('mh hm?') and gazes down at her paper to take notes (Figure 5). In line 6, the counsellor then verbally invites the interpreter to provide a rendition by saying that the interpreter could perhaps render the talk again for a moment ('but maybe again for a moment') in combination with gaze and gesture towards her (Figure 7). Thus, before expanding on those options that are 'also accessible for Erasmus students', the counsellor gives the interpreter the opportunity to render the preceding utterance. The interpreter immediately displays her acceptance of the offered turn by uttering a minimal response (line 7) and turning her gaze to the counsellor (Figure 8).

During her rendition of the preceding unit, the interpreter gazes from the student to the laptop screen (Figure 10). She explicitly orients the student's attention to the screen as the referent of 
the talk through her gaze and gestures (Figure 9-10). The interpreter ends her rendition in line 14 with falling intonation contour, while looking at the student, who maintains her gaze at the laptop screen (Figure 11). Note that the interpreter's rendition contains no indications that more will follow. She appears to select the student as next speaker by gazing at her. After a slight pause in line 15, the student produces an acknowledgment token ('mh') accompanied by nodding, while maintaining her gaze at the screen (Figure 12). The interpreter in this example thus provides a slot for the student, who is looking at the laptop screen, to offer a reaction to what has been said. In contrast to extract 4, the student's gaze at the laptop is not a sign of disengagement from the conversation. Although the student does not display availability to the interlocutors, her sustained gaze orientation towards the laptop screen appears to project her upcoming question. Thus, the interpreter in this example is closely monitoring the student's behavior for any cues of incipient speakership.

In line 17, the counsellor appears to self-select by opening her mouth. It is the student who finally takes the turn by producing an assessment ('interesting'). The student then articulates a question while gazing at the interpreter (Figure 13). However, the counsellor's hesitation and disfluency in line 21 indicate some issue with this question, which interrupts the course of her multi-unit turn.

\section{Conclusion}

In this study, we were interested in the multimodal process of chunking of extended tellings in interpreter-mediated dialogues with an on-site interpreter. Chunking in consecutively interpreted face-to-face dialogue is necessarily accomplished through finely tuned coordination between the primary speaker and the interpreter (see also Licoppe and Veyrier, forthcoming). The interpreter anticipates when the current turn will end by relying on various verbal and nonverbal cues, which points to the importance of visual monitoring of the speaker's behavior.

This study has also demonstrated how turn taking and sequence organization in interpretermediated face-to-face talk are essentially co-managed by the interpreter. The participant being gazed at towards the end of the interpreter's turn is selected to speak next. Furthermore, the interpreter's gaze shifts are constitutive for ongoing sequence organization in face-to-face interpreted talk. In the case of chunking, the interpreter projects turn completion and sequence progression with early gaze shifts. The timing of those gaze shifts is particularly interesting; in this way, the interpreter is blocking the completion points from being treated by the other 
speaker as transition relevance places and signaling to the other speaker to continue, thus ensuring a smooth continuation of the ongoing multi-unit turn. Through a detailed analysis of 'deviant' examples, we have also shown how the interpreter can contribute to or transform the projected activity by her gaze direction.

Thus, the interpreter's gaze direction at turn end is not only an important cue for an upcoming turn completion point (see also Pasquandrea 2011), but also a locus for the negotiation of a possible transition relevance place. With her gaze the interpreter does not select just any of the primary participants to speak next, but the one with the sequentially-relevant speaking rights. Therefore the interpreter's gaze conduct at turn-end elucidates the nexus between gaze organization as part of turn allocation and gaze as part of sequence production. With reference to the discussions on the organization of gaze in social interaction, Kendon's and Rossano's claim concerning the main organizational locus of gaze are not 'competing' (Streeck 2014), but are both essential for our understanding of the regulative role of gaze in social interaction.

\section{Acknowledgments}

The authors are most grateful to Elwys De Stefani for his extensive comments on an earlier version of this article. All remaining shortcomings are our own.

\section{Transcription conventions}

The excerpts have been transcribed according to conventions developed by Gail Jefferson. Conventions for the multimodal transcription are inspired by the conventions developed by Lorenza Mondada:

https://franzoesistik.philhist.unibas.ch/fileadmin/user_upload/franzoesistik/mondada_multimo

\section{dal_conventions.pdf}

[ ] simultaneous speech

(.) micropause (shorter than 0.2 seconds)

.h in-breath

indicates falling intonation

indicates rising intonation

lengthening or prolongation of a sound (sound stretch) 


\author{
$+\quad$ symbol + specifies the exact moment at which the student's gestures \\ begin and end \\ \# $\quad$ symbol \# specifies the exact moment at which the image (fig.) refers. \\ This is done by inserting the symbol both on the line of the talk and on \\ the line dedicated to the image (fig. in the margins) (see Mondada 2018).
}

\title{
Notes
}

1. However, this does not prevent another co-participant from self-selecting, which leaves us to conclude that turn organization is not all about the regulation of speaking rights, but "about qualified opportunities for certain activities" (Schmitt 2005, 81).

2. According to Rossano (2012: 69) the timing of listener responses "suggests that recipients understand early in a TCU whether it is projecting the beginning of a multi-unit turn, and behave as recipients, at least by not taking the floor".

3. The 'ecology of interaction' is important in this setting: as shown by Licoppe \& Veyrier (forthcoming) if the interpreter is physically distant from the speaker (via videolink), then s/he might be more inclined to use more obtrusive multimodal resources for explicit management of turns.

4. Eye-tracking does not say anything about peripheral vision; our observations are only based on observable gaze behavior, viz. gaze fixations

5. Counsellors in the present data set mostly gaze at the student (who has no understanding of Dutch) while speaking. In this way, they display orientation towards the student as the addressee of their talk. At the same time, they display disengagement from the interpreter, who is expected to take the next turn. By not gazing at the interpreter during and at the end of their turn, the counsellors are reducing their speakership to that of a conduit or a 'translation machine'. (see Authors, forthcoming for similar observations in the context of an interpretermediated therapeutic encounter)

6. In most cases, the student's gaze shift towards the counsellor follows the interpreter's gaze shift. As such, the interpreter's gaze shift appears to function as a gaze cue for the student's shift of attention towards the counsellor (on 'gaze cueing', see Frischen et al., 2007).

7. In other cases, the student gazes at the interpreter when the interpreter is speaking to her.

8. We find mutual gaze between the speaker and the interpreter in 52\% of turn transitions during chunking, and no gaze contact in $21 \%$ of the cases. In other instances, the speaker looks at the interpreter shortly before (6\%) or right after the end of his turn (17\%), after the interpreter has already shifted her gaze to the other interlocutor in order to start rendering the turn.

9. Only the final gaze shift of the final TCU at turn completion was taken into account.

10. Deviant case analysis is a common method in Conversation Analysis. It is through deviant cases that participants' own orientations to a 'norm' become visible 
11. As noted by Levinson (2012) the type of action that is being done by the turn "is revealed by the response of a next speaker".

12. The example provides a nice example of the 'transformative' (Goodwin 2013) power of gaze in the process of sequence organization.

\section{References}

Authors. 2017.

Authors. (forthcoming)

Angelelli, Claudia. 2000. "Interpretation as a Communicative Event: A Look through Hymes' Lenses.” Translators' Journal 45(4): 580-592.

Auer, Peter. 2005. "Projection in interaction and projection in grammar." Text 25 (1): 7-36 .

Auer, Peter. 2017. "Gaze, addressee selection and turn-taking in three-party interaction." InLiSt (60): 1-32.

Baraldi, Claudio, and Laura Gavioli. 2012. "Introduction: Understanding coordination in interpreter-mediated interaction." In Coordinating Participation in Dialogue Interpreting, ed. by Claudio Baraldi and Laura Gavioli, 1-21. Amsterdam and Philadelphia: John Benjamins.

Bavelas, B. Janet, Linda Coates, and Trudy Johnson. 2002. "Listener responses as a collaborative process: The role of gaze.” Journal of Communication: 566-580.

Bolden, Galina. 2000. "Toward understanding practices of medical interpreting: interpreters' involvement in history taking." Discourse Studies 2 (4): 387-419.

Bot, Hanneke. 2005. Dialogue Interpreting in Mental Health. Amsterdam and New York: Rodopi Publishers.

Clayman, Steven E. 2013. “Turn-Constructional Units and the Transition-Relevance-Place.” In The Handbook of Conversation Analysis, ed. by Jack Sidnell and Tanya Stivers, 150-166. Oxford: Wiley-Blackwell.

Couper-Kuhlen, Elizabeth, and Tsuyoshi Ono. 2007. “"Incrementing' in conversation. A comparison of practices in English, German and Japanese.” Pragmatics 17 (4): 513-552.

Davidson, Brad. 2012. "A model for the construction of conversational common ground in interpreted discourse.” Journal of Pragmatics 34: 1273-1300.

Davitti, Elena. 2013. “Dialogue Interpreting as Intercultural Mediation: Interpreter's use of upgrading moves in parent-teacher meetings.” Interpreting 15 (2): 168-199. 
Davitti, Elena, and Sergio Pasquandrea. 2017. "Embodied participation: What multimodal analysis can tell us about interpreter-mediated encounters in pedagogical settings." Journal of Pragmatics 107: 105-128.

Duncan, Starkey. 1972. "Some signals and rules for taking speaking turns in conversations." Journal of Personality and Social Psychology 23 (2): 283-292.

Englund Dimitrova, Birgitta. 1997. "Degree of Interpreter Responsibility in the Interaction Process in Community Interpreting." In Critical Link: Interpreters in the Community, ed. by Silvana E. Carr, 147-164. Amsterdam/Philadelphia: Benjamins.

Ford, Cecilia E. 2004. "Contingency and units in interaction. "Discourse Studies 6(1): 27-52.

Ford, Cecilia E., Barbara Fox, and Sandra A. Thompson. 1996. "Practices in the construction of turns: The TCU revisted." Pragmatics 6 (3): 427 - 454.

Frischen, Alexandra, Andrew P. Bayliss, and Steven P. Tipper. 2007. "Gaze Cueing of Attention: Visual Attention, Social Cognition, and Individual Differences." Psychological Bulletin 133 (4): $694-724$.

Goodwin, Charles. 1979. "The Interactive Construction of a Sentence in Natural Conversation." In Everyday Language: Studies in Ethnomethodology, ed. by Georg Psathas, 97-121. New York, Irvington Publishers.

Goodwin, Charles. 1981. Conversational Organization. Interaction between Speakers and Hearers. New York, London: Academic.

Goodwin, Charles. 2013. "The co-operative, transformative organization of human action and knowledge." Journal of Pragmatics 46: 8-23.

Hayashi, Makoto. 2013. "Turn Allocation and Turn Sharing." In The Handbook of Conversation Analysis, ed. by Jack Sidnell and Tanya Stivers, 167-190. Oxford: WileyBlackwell.

Holler, Judith, and Kobin H. Kendrick. 2015. 'Unaddressed participants' gaze in multi-person interaction: Optimizing recipiency." Frontiers in Psychology 6: 98.

Kendon, Adam. 1967. "Some functions of gaze-direction in social interaction." Acta Psychologica 26: 22-63.

Lang, Ranier. 1978. "Behavioral aspects of liaison interpreters in Papua New Guinea: some preliminary observations." In Language Interpretation and Communication, ed. by David Gerver and Wallace H. Sinaiko, 231-244. New York/London: Plenum Press.

Lerner, Gene H. 1991. “On the Syntax of Sentences in Progress.” Language in Society 20: 441458. 
Lerner, Gene H. 2003. "Selecting next speaker: The context-sensitive operation of a contextfree organization.” Language in Society 32: 177-201.

Levinson, Stephen C. 2012. "Action formation and ascription." In The Handbook of Conversation Analysis, ed. by Jack Sidnell and Tanya Stivers, 103-131. Oxford: WileyBlackwell.

Levinson, Stephen C., and Francisco Torreira. 2015. "Timing in turn-taking and its implications for processing models of language." In Turn-taking in human communicative interaction, ed. by Judith Holler, Kobin H. Kendrick, Marisa Casillas and Stephen C. Levinson, 10-27. Frontiers in Psychology.

Llewellyn-Jones Peter, and Robert G. Lee. (2014) Redefining the Role of the Community Interpreter: The Concept of role-space. Lincoln: SLI Press.

Li, Shuangyu. 2015. "Nine Types of Turn-taking in Interpreter-mediated GP Consultations." Applied Linguistics Review 6 (1): 73-96.

Licoppe, Christian, and Clair-Antoine Veyrier. "The interpreter as a sequential coordinator in courtroom interaction. 'Chunking' and the management of turn shifts in extended answers in consecutively interpreted asylum hearings with remote participants." Interpreting. (forthcoming).

Mandelbaum, Jenny. 2013. "Storytelling in Conversation." In The Handbook of Conversation Analysis, ed. by Jack Sidnell and Tanya Stivers, 492-509. Oxford: Wiley-Blackwell.

Mason, Ian. 2012. “Gaze, positioning and identity in interpreter-mediated dialogues." In Coordinating Participation in Dialogue Interpreting, ed. by Claudio Baraldi and Laura Gavioli, 177-199. Amsterdam/Philadelphia: Benjamins Publishing.

Merlino, Sara. 2014. "Traduction orale et organisation de la parole: la gestion multimodale des transitions." In Corps en interaction: participation, spatialité, mobilité, ed. by Lorenza Mondada, 65-105. Lyon: ENS Editions.

Mondada, Lorenza. 2007. "Multimodal resources for turn-taking: pointing and emergence of next speakers.” Discourse Studies: 194-225.

Mondada, Lorenza. 2018. "Multiple Temporalities of Language and Body in Interaction: Challenges for Transcribing Multimodality.” Research on Language and Social Interaction: 51 (1): 85-106.

Pasquandrea, Sergio. 2011. "Managing multiple actions through multimodality: Doctors' involvement in interpreter-mediated interactions." Language in Society 40 (4): 455-481.

Rossano, Federico. 2012. Gaze behavior in face-to-face interaction. PhD Thesis, Radboud University Nijmegen, The Netherlands. 
Sacks, Harvey, Emanuel A. Schegloff, and Gail Jefferson. 1974. “A Simplest Systematics for the Organization of Turn-Taking for Conversation." Language 50: 696-735.

Schegloff, Emanuel A. 1982. "Discourse as an interactional achievement: Some uses of 'uh huh' and other things that come between sentences." In Analyzing Discourse: Text and Talk, ed. by Deborah Tannen, 71-93. Washington DC: Georgetown University Press.

Schegloff, Emanuel A. 1996. "Turn Organization: One Intersection of Grammar and Interaction." Interaction and Grammar, 52-133.

Schegloff, Emanuel A. 2000. "Overlapping talk and the organization of turn-taking for conversation." Language in Society 29: 1-63.

Schmitt, Reinhold. 2005. "Zur multimodalen Struktur von turn-taking." Gesprächsforschung 6: 17-61.

Selting, Margaret. 2000. "The construction of units in conversational talk.” Language in Society 29: 477-517.

Sidnell, Jack, and Tanya Stivers (eds). 2012. The Handbook of Conversation Analysis. Chichester: Blackwell-Wiley.

Stivers, Tanya. 2008. "Stance, Alignment and Affiliation during Storytelling: When Nodding is a Token of Affiliation." Research on Language and Social Interaction 41 (1): 31-57.

Stivers, Tanya. 2013. "Sequence organization.” In The Handbook of Conversation Analysis.

Oxford, ed. by Jack Sidnell and Tanya Stivers, 191-209. Chichester: Wiley-Blackwell.

Stivers, Tanya, and Nick J. Enfield. 2010. “A coding scheme for question-response sequences in conversation." Journal of Pragmatics 42(10): 2620-2626.

Stivers, Tanya, and Federico Rossano. 2010. "Mobilizing Response.” Research on Language and Social Interaction 43 (1): 3-31

Streeck, Jürgen. 2014. "Mutual gaze and recognition. Revisiting Kendon’s “Gaze direction in two-person conversation"”. In From Gesture in Conversation to Visible Action as Utterance: Essays in honor of Adam Kendon, ed. by Mandana Seyfeddinpur and Marianne Gullberg, 3556. John Benjamins Publishing Company.

Wadensjö, Cecilia. 1998. Interpreting as interaction. London and New York: Longman. Wittenburg, Peter, Hennie Brugman, Albert Russel, Alex Klassmann, Han Sloetjes. 2006. ELAN: a Professional Framework for Multimodality Research. In: Proceedings of LREC 2006, Fifth International Conference on Language Resources and Evaluation. 
